\title{
El Ajuste o Desajuste de las Prácticas Normativas en Ignacio Ellacuría: hacia una nueva dimensión de lo normativo
}

\author{
Juan Antonio Senent ${ }^{1}$
}

Resumen: Este trabajo realiza un análisis sobre el ajuste o desajuste de los derechos humanos a partir de la tesis de Ignacio Ellacuría. Se trata primero de ubicar este análisis en el contexto crítico que lo anima, el horizonte de la praxis histórica. Desde ahí se propone una fundamentación del ajuste en su relación con la praxis humana, así como el estudio crítico del papel que ese ajuste o desajuste de los esquemas normativos juega actualmente en el conjunto del proceso normativo en el seno de las prácticas sociales en la presente fase civilizatoria. A su vez, se aborda un análisis de la lucha por articular otros esquemas normativos que respondan más ajustadamente a las exigencias de la justicia frente a los otros y a la naturaleza.

Palabras-chave: Prácticas normativas. Ajuste normativo. Derechos humanos. Horizonte de la praxis. Ignacio Ellacuría. Xavier Zubiri.

\begin{abstract}
This work provides an analysis of adjustment or disadjustment of human rights from Ignacio Ellacuría thesis. We must first place this analysis in the critical context that animates it, the horizon of historical praxis. From there, a rationale for its adjustment in relation to human praxis is proposed, as well as a critical study of the role such adjustment or maladjustment of regulatory schemes currently plays in the overall regulatory process within the social practices in the contemporary civilization stage. In turn, we conduct an analysis of the struggle to articulate other regulatory schemes that respond more tightly to the demands of justice against others and nature.
\end{abstract}

Keywords: Regulatory practices. Policy adjustment. Human rights. Horizon of praxis. Ignacio Ellacuría. Xavier Zubiri.

1 Profesor del Departamento de Filosofía del Derecho de Universidad de Sevilla (España). Este artículo tiene su origen en la ponencia impartida en el Congreso Internacional Ignacio Ellacuría 20 años después, Sevilla 26-28 de octubre de 2009. Agradezco a los profesores Antonio-Enrique Pérez Luño y Francisco José Contreras las observaciones realizadas a la ponencia presentada, las cuales me han permitido depurar y contrastar algunos análisis.E-mail: senent@us.es.

Recebido em: 08/02/2011.

Revisado em: 04/03/2011.

Aceito em: 29/04/2011. 


\section{Introducción}

Voy a tratar aquí del problema del ajuste o el desajuste en relación con las prácticas normativas $\mathrm{y}$, dentro de ese campo, se enfocará la cuestión más específicamente desde las prácticas que articulan procesos normativos en la perspectiva de los derechos humanos. En este contexto, se abordarán más específicamente las implicaciones de este "ajuste” o "justeza", en lo que se refiere a su delimitación, fundamentación y su función en el campo de los derechos humanos. Con ello pretendemos avanzar en la discusión y el análisis de esta cuestión a partir de las tesis sostenidas por Ignacio Ellacuría ${ }^{2}$ en sus escritos.

La hipótesis que lanzamos en este trabajo es que el examen de este problema también puede ayudar a esclarecer la comprensión del cualquier fenómeno jurídico, lo que supone una invitación a ampliar la consideración de lo jurídico desde esta perspectiva. Ello implica, como decimos, una perspectiva ampliad ${ }^{3}$, puesto que no se lo considera aisladamente desde el momento de institucionalidad del derecho o del sistema jurídico vigente en una sociedad, sino dinámicamente en el conjunto del proceso social de institucionalización del derecho en el contexto de la realidad social y natural. Así, este proceso empieza antes del reconocimiento institucional, y no acaba en el reconocimiento positivo, sino que permanece siempre abierto en tanto subsistan las prácticas sociales. No se trata sólo de una cuestión de apertura interna del derecho establecido, es decir, las lingüís-

\footnotetext{
2 Para un conocimiento y discusión de la filosofía práctica de Ignacio Ellacuría pueden consultarse, entre otros: SENENT, 1997, 2007; ROSILLO, 2009; SENENT; MORA, 2010; DUSSEL, 2007; SOBRINO; ALVARADO,1999; GIMBERNAT; GÓMEZ, 1994; GONZÁLEZ, 1990; SAMOUR, 2003; CASTELLÓN, 2003; MORA, 2004.

3 Una perspectiva ampliada semejante a la aquí sostenida es la mantenida por Enrique Dussel (2001, p. 145-157, 159-169) en sus trabajos "Derechos humanos y ética de la liberación (pretensión política de justicia y la lucha por el reconocimiento de los nuevos derechos)" y "La transformación del sistema del Derecho" en Hacia una filosofía política crítica. Sin embargo, no se aborda en estos trabajos la cuestión del ajuste o desajuste como dimensión propia de las prácticas normativas. Todo ello, reconociendo el decisivo aporte que en clave también de una teoría crítica latinoamericana o pensamiento de la liberación, como lo fue el pensamiento de Ellacuría, tiene Enrique Dussel por el diálogo crítico que ha desplegado con buena parte de la filosofía actual más influyente.
} 
ticas y sistémicas, sino de la apertura que se despliega en el proceso social en el que acontece lo jurídico; esto es, de la apertura ${ }^{4}$ de las prácticas sociales en las que el derecho, y particularmente los derechos, se van definiendo y redefiniendo. Por ello, la perspectiva desde la que considera el derecho Ellacuría, y en particular los derechos humanos, difiere de las comprensiones vigentes más influyentes, sobre todo de las aproximaciones formalistas al derecho. Veamos algunas tesis que nos pueden ofrecer un cierto contraste con la perspectiva aquí asumida.

Recientemente Robert Alexy (2005, p. 45-47) ha incidido en la cuestión de la textura abierta del derecho positivo, sostenida por Hart (1998, p. 153 et seq.), como una cuestión a resolver por los operadores jurídicos, y por tanto sustraída a una consideración social y natural más amplia de las prácticas normativas, donde sólo parecen jugar los que tienen cierto capital jurídico acumulado, por decirlo al modo de Bourdieu. En este sentido se mantiene, a pesar de cierta superación por Alexy del paradigma positivista desvinculado de la eticidad ${ }^{5}$, en una escisión o fractura socio-jurídica en el proceso de lucha por ideales o por los derechos humanos entre institución, sea esta legal o política y prácticas sociales instituyentes.

En este contexto podemos situar la apertura del derecho desde el proceso social en el que acontece. Esta proyección de lo que debe ser realizado y reconocido en función de la situación que se está experimentado como insuficiente, tanto en términos materiales como ideales, es lo que mantiene activo tanto el proceso de transformación del sistema del derecho como la lucha jurídica por su interpretación, y en este sentido, este proceso de desenvolvimiento de lo jurídico se da en un contexto mayor. Por ello, el sistema del derecho no es causa sui y se integra en una tarea ética mayor que se actualiza en las propias prácticas y obliga a ir transformando, tanto diacrónica como sincrónicamente (SENENT, 2006, p. 67109), la positividad vigente o el estado de cosas amparados en el derecho

4 Esto es algo que abordé en diálogo con la doctrina actual en Problemas fundamentales de los derechos humanos (SENENT, 2007, p. 45 et seq.).

5 Sobre todo del sostenido por Kelsen $(1988,2000)$ al mostrar el carácter intrínseco de la pretensión de justicia de los actos jurídicos - al menos en nuestra cultura jurídica. 
reconocido. Impidese así el cierre categorial perfecto del sistema jurídico, al modo en que aspiraba Kelsen (1988, p. 209-212) ${ }^{6}$. No se puede remitir la delimitación de la validez solo al plano jurídico pues puede haber un juicio de validez que trascienda el punto de vista interno-formal del derecho. Un juicio de validez trascendido no se integra necesariamente en la dirección de una mejora de la eticidad del derecho (como por ejemplo sería en el dinamismo de los derechos humanos con respecto al sistema legal) y también puede haber un juicio de validez que se oriente en la dirección de un vaciamiento de las exigencias axiológicas ya presentes en el sistema legal. En este contexto, el intento de Luigi Ferrajoli de integrar los contenidos axiológicos de un sistema dado en el propio juicio de validez, a nuestro modo de ver, implica, en el fondo, un llamado a la responsabilidad ética del jurista o de los actores que trasciende el paradigma positivista ${ }^{7}$ pues ello exige un discernimiento de lo más valioso y un

6 Kelsen asume aquí como propio el punto de vista weberiano (citando con ello la obra de Weber Wirtschaft und Gesellschaft, p. 368) de la referencia a "normas jurídicas idealmente válidas" como lo distintivo del derecho o del orden jurídico. Para Max Weber, esta referencia puede ser descrita en términos objetivos y perfectamente neutrales con independencia de su objeto, aun "normativo". Éste había puesto las bases de su perspectiva "pura" del conocimiento de lo social o natural mediante su delimitación del campo científico como descripción frente a la elección o prescripción propia del campo político o personal, que sería inobjetivable e irracional. Señala Weber (1985, p.73), que "por desgracia, no existe un puente que desde el análisis puramente empírico de la realidad efectuado con los instrumentos de la explicación causal conduzca a la confirmación o refutación de la "validez" de cualquier juicio de valor". Kelsen, por su parte, asumiría también este punto de vista también en su tratamiento del problema de la justicia ("la justicia es un ideal irracional [en tanto que] no es accesible al conocimiento", p. 15). Y a su vez, siguiendo un planteamiento análogo al weberiano, divide lo jurídico en dos campos perfectamente escindidos, el "científico" (que se encarga de describir los "enunciados jurídicos" -Rechtssatz-: "la ciencia del derecho tiene que conocer el derecho -por así decirlo, desde fuera- y fundándose en ese conocimiento, describirlo", (ibid, p. 85); y el "práctico", donde se producen las "normas jurídicas"-Rechtsnorm- ("los órganos del derecho, como autoridad jurídica, tienen ante todo que producir el derecho", loc.cit.).

7 Como señala Perfecto Andrés Ibáñez (1999, p. 10-11), Ferrajoli aun partiendo de los presupuestos del normativismo kelseniano y de la filosofía analítica del derecho, ha necesitado superar los límites científicos de sus orígenes, "como lo demuestra su renuncia al espejismo de una teoría pura o formal del derecho, no valorativa o simplemente descriptiva" y a su vez, la asunción de un criterio de validez no meramente formal sino "en términos de racionalidad material-constitucional". 
compromiso con su desarrollo; desde ahí puede entenderse la reacción, por ejemplo, ante la "crisis constitucional" o ante la "crisis de Estado social" (IBAÑEZ, 1999, p. 15 et seq). La apertura del proceso social en que acontece el derecho no asegura necesariamente ningún proceso asintótico de mejora, por ello, la tarea de ir configurando realmente el sistema de orientaciones normativas de unas prácticas sociales implica, como veremos, una responsabilidad ética en cualquier dirección, de ahí que, como a veces ha sucedido históricamente, como en los juicios de Nüremberg, pueda haber una exigencia de responsabilidad por el modo en que se ha practicado el derecho. Es evidente que este juicio es meta-jurídico (en el sentido en que trasciende la formalidad del derecho vigente conforme a la teoría estándar de la validez), aun cuando pueda articularse jurisdiccionalmente. Ello prueba que en el juicio de validez hay una responsabilidad ética, sea o no correctamente ejercida y que, en función de ello, se puedan "pedir cuentas".

Sobre esta última cuestión se pronunció Herbert Hart, negando aparentemente un juicio de validez ampliado. Digo aparentemente, porque incurre en una cierta contradicción performativa muy reveladora. Hart se decanta por razones morales por un juicio de validez jurídica restringido, esto es, su concepto de derecho restringido lo justifica científicamente porque es su mejor opción moral ${ }^{8}$. Parece que lo propio es realizar un

8 "un concepto de derecho que permite distinguir entre la invalidez de las normas jurídicas y su inmoralidad, nos habilita para ver la complejidad y variedad de estas distintas cuestiones (...) puede concederse que los delatores alemanes, que guiados por móviles egoístas procuraron el castigo de otros por leyes monstruosas, hicieron algo prohibido por la moral; sin embargo la moral puede exigir también que el estado castigue únicamente a aquellos que, al hacer el mal, hicieron lo que estaba prohibido por el estado en ese momento (...) Si hemos de introducir fisuras en este principio para impedir algo que se considera un mal mayor que su sacrificio, es vital que las cuestiones en juego sean identificadas claramente. Un caso de castigo retroactivo no debe ser presentado como si se tratara de un caso de castigo ordinario. Por lo menos puede argüirse en favor de la simple doctrina positivista de que las reglas moralmente inicuas pueden ser derecho, que ella no oculta la elección entre males que, en circunstancias extremas, podemos vernos en la necesidad de efectuar" (1998, p. 261). Es interesante constatar como Hart es perfectamente consciente del problematismo inscrito en el juicio de validez que no se puede ventilar cómodamente como mera "descripción" al modo weberiano o kelseniano, cuando reconoce alguna posibilidad de "introducir fisuras en este principio". 
discernimiento sobre el juicio de validez que se asume en cada acto, pues tenemos que elegir en función de la mejor opción moral (si queremos ejercer correctamente nuestro emplazamiento). Ahora bien, aun cuando se decante provisionalmente por un concepto de validez restringido, esto se funda, de facto, en una perspectiva ampliada desde la cual, en su caso, decide, por responsabilidad moral, restringir (o no) el concepto de validez jurídica para el caso concreto.

Pues bien, la perspectiva de Ellacuría del derecho, que se puede reconstruir a partir de su tratamiento metodológico de los derechos humanos, se separa, como iremos viendo, de una fractura perfecta, tanto entre juridicidad y moralidad o eticidad, como entre conocimiento y producción o aplicación del derecho, en función de una cierta lectura fenomenológi$\mathrm{ca}^{9}$ de cómo acontece el derecho en la propia praxis social.

Para Ellacuría la complejidad del fenómeno de los derechos tiene que ser enfrentada desde tres momentos interna y sistemáticamente vinculados (verdad, justicia y justeza), que son dimensiones primarias de los derechos humanos, donde se pueden, a nuestro juicio, articular otros fenómenos. Ello exigiría un tratamiento general y sistemático que no podemos ofrecer aquí. En este trabajo nos centraremos en el momento de justeza o ajuste y en su tratamiento se irán viendo las conexiones con los otros momentos. El ajuste de un derecho humano es la condición de su justeza y ésta no remite en su totalidad a una dimensión de verdad, ni de idealidad o justicia (que son también partes constitutivas de los derechos humanos que deben ser esclarecidas y alcanzadas, aunque a su vez, siempre hay que tomar las tres dimensiones de verdad, justicia y ajuste

En este sentido, Hart muestra un camino, a pesar de que no lo recorrió hasta sus últimas consecuencias, para una superación de la teoría formalista de la validez.

9 En ella, su influjo más decisivo - aunque no único - es su maestro, Xavier Zubiri quien radicalizó a su vez, tanto el análisis fenomenológico propuesto por Edmund Husserl, como la lectura que del mismo emprendió su discípulo Martin Heidegger (ello puede observarse ya en su tesis doctoral de 1965, Principialidad de la esencia en Xavier Zubiri, donde Ellacuría realiza un profundo examen crítico a la luz del planteamiento zubiriano de estos dos autores, centrales para el siglo XX, por la permanencia tanto de Husserl como de Heidegger en el ámbito del idealismo). Sobre la "fenomenología" postidealista zubiriana, montará Ellacuría su análisis de la praxis humana, que es la base epistemológica de su teoría normativa. 
de modo integrado en última instancia (1965, epígrafe 3). En el ajuste o desajuste se trata de una dimensión "práxica o política" (ELLACURÍA, 2001, p. 434). El ajuste o desajuste de un hacer, o de un poder hacer está en relación con su realizabilidad y viabilidad ${ }^{10}$ en el conjunto de las prácticas sociales en el sentido en que éstas determinan su condición social de posibilidad o de imposibilidad a la vez que ese hacer o poder hacer favorece o no, el hacer o poder hacer de otros ${ }^{11}$. Por ello, dice Ellacuría que es una cuestión práxica o política. Es decir, no se trata solo de un ámbito de

${ }^{10}$ Como aclaración, aun sumaria, de la diferencia entre la eficacia y la justeza, diremos que ésta implica un juicio ampliado sobre la eficacia normativa - juicio interno limitado(apuntaré alguna diferencia tomando para la discusión los conceptos propuestos por Serrano (1999, p. 63), pudiendo el criterio de justeza incluir en su perspectiva la eficacia, pero no pararse en ella, al tener como referencia el despliegue real de la norma o de la práctica social. La justeza como realizabilidad y viabilidad o sostenibilidad, se diferencia de la mera eficacia de cumplimiento de un derecho que puede asumirse desde una perspectiva restringida del derecho (no es sólo la cuestión, vista desde la norma, de si una norma es practicada o no, es decir de su "eficacia de cumplimiento") porque sitúa el contexto de vigencia de una norma y su realización en el entorno social en las condiciones materiales o sociales que permiten o impiden su realización. En cuanto a la "eficacia de la sanción" como simple constatación de que "en el entorno del sistema jurídico del hecho de que la sanción prevista por la norma X se aplica en los supuestos de su incumplimiento" (ib.), el criterio de justeza puede asumir la sanción como reajustamiento de una práctica antijurídica con su entorno, pero va más allá del punto de vista interno al preguntarse por el carácter ajustado o no de la sanción prevista en función de en qué situación quede o se ponga al sujeto de la sanción. A su vez, con respecto a la "efectividad", ante el hecho "de que los poderes públicos alcancen los fines para los que se promulgaron para los que las promulgaron" (ib.), la justeza es un criterio mayor porque la necesidad de alcanzar los fines (y su calidad material) está inscrita en la necesidad de ajustamiento de las prácticas sociales. Con respecto a la "eficiencia", esto es, si la norma "alcanza con un coste razonable los fines para los que fue promulgada" (ib.), el criterio de la justeza muestra, por su conexión con el momento de justicia, como la necesidad de un "ajuste" no puede justificarse cómodamente en términos absolutos para una situación normativa cuando ello implique costes que impidan el disfrute de otros derechos o el respeto de otros bienes. En este sentido, la eficiencia, es tensionada por el criterio de justeza al incorporar una dimensión normativa o exigencial en el marco de lo real.

${ }^{11}$ En esta línea, nos dice Ellacuría que el ser humano "no se da 'realmente' como individuo aislado, aunque tampoco su realidad sea sin más el conjunto de las relaciones sociales, aunque sea evidentemente un hombre social, determinado concreta e históricamente por lo que hace, por lo que le hacen hacer o por lo que le dejan hacer" (ELLACURÍA, I., "Introducción. Persona y comunidad", Escritos filosóficos III, Op. Cit., p. 68). 
acción reconocible o reconocido ${ }^{12}$, sino que su ejercicio o realizabilidad está condicionado por la estructuración social o, dicho de otro modo, por la ordenación material de las relaciones de poder en una sociedad de la que se es paciente y que de algún modo también se puede ser agente, y a su vez, por la viabilidad que en conjunto ofrece.

Hablamos en el título de este trabajo de lo "normativo" porque esta perspectiva podría aplicarse a otros usos normativos, como pueden ser los morales o los sociales. Por cuestiones prácticas voy a concentrarme en

12 Esto remite a su vez a la cuestión de la validez. Ello requiere una consideración in extenso, que no podemos ofrecer en este espacio, por lo que sólo haré aquí algunas precisiones. Antes hemos hecho unas observaciones preliminares que sirven para distinguir la perspectiva ellacuriana del concepto formalista y positivista de la validez more kelseniano. Decimos que es un ámbito reconocible, es decir, que está siendo todavía excluido por los otros de la relación social del reconocimiento de su validez, o en su caso reconocido. En esta perspectiva de análisis la validez está implicada en la dimensión verdad que se articula en la práctica normativa y en la medida en que es tomada en serio por los actores de un contexto sociopolítico, no simplemente como un subterfugio ideológico para justificar el mantenimiento de un proceso social que niega de facto en sus realizaciones lo que afirma ser idealmente una verdadera norma (y por tanto válida) y que por ello debe orientar efectivamente las prácticas sociales como proyecto de sociedad al que se va acercando visiblemente por sus aproximaciones prácticas. Sostener como reconocido un conjunto de normas implica un compromiso con su realización en el proceso social, la veracidad (visible mediante su verificación en los resultados sociales, por el "método de historización de los conceptos"; esto lo he tratado en Ellacuría y los derechos (SENENT,1998, p. 145-185) o no de ese compromiso o de esa apuesta por el reconocimiento, es un criterio mayor donde se integra la cuestión de la validez. La cualificación de la (mayor o menor) veracidad o falsedad histórico-social de lo reconocido retórica o idealmente, confirma o erosiona y desacredita la supuesta validez. Esto muestra el carácter veraz o falsario y manipulador de los actores del sistema sostenido, y con ello, del sistema mismo.

Por ello, el "juicio de validez", no se puede resolver por referencias "internas", por criterios lógicos únicamente como pertenencia o no a un sistema normativo sino situándolos en el contexto del proceso social. En este sentido, la validez no es algo estático, sino que hay, o puede haber una lucha por la validez, esto es, por ir dando validez en las prácticas sociales a lo que en su caso, tiene supuestamente reconocida una validez teórica en el discurso normativo abstractamente considerado. En esta línea, la tarea de dar validez o por válido un derecho reconocido (o por reconocer) forma parte pues de una tarea ética en la que se integra y en la que están emplazados los propios actores de un sistema normativo. 
el mundo jurídico, y dentro de este campo, trataré la cuestión desde el mismo planteamiento que hace Ellacuría en su abordaje de los derechos humanos. El instrumental analítico y metodológico que vayamos ganando en la marcha podría ser después puesto en relación con otros campos normativos o hacia el conjunto de la experiencia jurídica.

Quisiera hacer otra precisión sobre lo referido en el título mediante la pretensión de ir "hacia una nueva dimensión de lo normativo". En realidad, si no queremos incurrir en planteamientos idealistas, tenemos que ir al reconocimiento de esta dimensión del ajuste como parte de facto de las prácticas jurídicas, al menos como posible aspiración de la mayoría de los sistemas jurídicos y de sus actores. No se trata de constituir por el pensamiento esa dimensión, pero sí de articular conscientemente la tensión entre interpretación o comprensión del derecho y su aplicación; en esa tensión, en la lucha por "decir y decidir el derecho", por la iuris-dictio, tiene un papel que jugar la dimensión del ajuste que puede ser puesta al servicio de unos o de otros, o de todos, al menos como proceso. A este proceso de ajuste están emplazados los actores y sus sistemas jurídicos.

\section{Horizonte de la Praxis como Marco para el Esclarecimiento de las Prácticas Normativas}

Para el tratamiento de esta cuestión nos situamos reflexiva y activamente en el denominado a partir de la filosofía ellacuriana "horizonte de la praxis histórica" (SENENT, 1998, p. 101-144; GRACIA, 2010, p. 11-26). Éste no es sino un esfuerzo crítico, que se suma a otros ${ }^{13}$, por

13 El contexto crítico inmediato para Ellacuría es el filosofar desde América Latina como periferia y exterioridad del centro y la totalidad occidental. Desde ahí surge con fuerza un movimiento plural desde el último tercio del siglo XX, donde distintas contribuciones critican el pensamiento producido y mantenido en el centro, y cuyas limitaciones e insuficiencias permiten mantener en una mala situación cultural regiones dominadas, y critican a su vez el pensamiento latinoamericano que mimetiza colonialmente el pensamiento del centro. Como ha señalado Carlos Beorlegui, (2010, p.96) “para Ellacuría encararse filosóficamente con la realidad equivalía a hacer una filosofía que, aunque apoyada en las mejores aportaciones de la historia de la filosofía, sobre todo las de Zubiri, fuera una filosofía al mismo tiempo latinoamericana, filosofía que, por otro lado, no 
tratar de superar los límites del "horizonte del sujeto" moderno, y abrir así la posibilidad de un marco intelectivo y de realización postmoderno ampliado que no renuncia a ciertos hallazgos de la Modernidad y, en ese sentido, ni es simplemente "antimoderno" ni puramente indolente al estilo posmodernista. Decimos activa y reflexivamente, porque hay que realizar un cierto esfuerzo para salir del modo habitual en que la Modernidad entiende estos fenómenos. No se trata sin más de darle la vuelta al planteamiento moderno para tener, en última instancia, una Modernidad al revés como la lectura del marxismo que desde el materialismo dialéctico se propuso, lo que no es sino otra forma de seguir con la misma limitación ${ }^{14}$.

Esta propuesta de marco intelectivo desde donde se plantea la tarea normativa, trata de enfrentar el peligro de la orientación idealista por la que transcurre buena parte de la Modernidad ${ }^{15}$ con el riesgo, en términos prácticos y políticos, de hacer pasar como buena y definitiva una realidad humana y social rota en nombre de valores meramente postulados o proclamados; o de justificar el "fin de la historia" de las instituciones como si de esencias ahistóricas e inmutables se trataran y no de construcciones hechas y recreadas en función de los propios sistemas sociales. Pero además, desde esta orientación idealista que se articula de múltiples formas, es más fácil recaer en un formalismo normativista que atienda sólo a una

podía ser más que una filosofía liberadora o de la liberación, no sólo para Latinoamérica, sino para el resto de la humanidad". Para conocer ese movimiento filosófico hay dos referencias imprescindibles, de Beorlegui, (2006) y la de SÁNCHEZ (1999).

14 Por ello, como a continuación diremos, no sólo se enfrenta con la orientación idealista de la Modernidad, sino también con un materialismo determinista que hace de los sujetos históricos meros objetos de las fuerzas que los empujan y de los condicionamientos físicos en que quedan subsumidos. Junto a una libertad que "flota en sí misma", al modo del subjetivismo idealista moderno, hay que tener en cuenta la lucha por la liberación de esa libertad que parte de la propia formalidad en que se realizan los actos humanos según ha analizado Xavier Zubiri (1980, 1982, 1983). Esta formalidad inscrita en los actos humanos, es un hecho decisivo, precario pero ineludible, que dota de apertura a cada situación histórica.

15 Es una de las constantes críticas de la filosofía ellacuriana, quien se apoya sobre todo en Zubiri para señalar esta limitación, de ahí su lectura del proyecto filosófico zubiriano en clave de la liberación de otro horizonte, que podríamos denominar "postidealista". Sobre esta cuestión es muy relevante su trabajo "La superación del reduccionismo idealista en Zubiri” (ELLACURÍA, 1988, p. 403-430). 
normatividad absoluta y abstracta, separada por tanto de los actores reales $\mathrm{y}$ de los destinatarios y sujetos de esa normatividad en donde acontece ${ }^{16}$; o de entender las prácticas normativas principalmente como "discurso" sin dar cuenta de lo que se está jugando y realizando con ese "discurso". En este sentido, se trata de superar la disociación o fractura ontológica y epistemológica ${ }^{17}$ entre "ser" y "deber ser"18, entre "norma" y "hecho", mostrando el lugar de imbricación entre ambos planos desde la acción humana, aunque esto requiera un largo y riguroso análisis que en buena medida está por hacer. Si el momento debitorio o exigencial es ineludible en cada acción (SENENT, 2007, p. 85-101), pese a que se pueda "pasar de largo" de ese momento con la posibilidad subsiguiente de cierre ético de la situación y con ello el cierre de posibilidades de tratamiento debido, siempre, en tanto que haya acción humana, cabe la apertura de nuevas posibilidades que desplieguen normativamente la situación de los actores a otro reconocimiento o exigencia debida. Por ello, la tarea normativa, el ir descubriendo lo que debe ser realizado, institucionalizado y superando a su vez lo institucionalizado, es siempre una tarea inacabable en tanto haya praxis humana. De ahí que esta tarea deba partir reflexivamente de

16 No puedo dejar de referirme a un trabajo que muestra fehacientemente las insuficiencias para los desafíos actuales del paradigma más típico de esta opción, como es el kelseniano, de Antonio-Enrique Pérez Luño, (2009, p. 361-390).

17 La tradicional distinción entre ser y deber ser, y su correlato en la diferencia entre describir y prescribir que en la filosofía moderna se funda en el pensamiento de David Hume tiene una larga secuela histórica (antes mencionamos a dos destacados cultivadores de esa tradición como Weber o Kelsen) que sin embargo, muestra ya signos de agotamiento. Son múltiples los enfrentamientos críticos a estas dicotomías ya seculares. Entre ellos, y desde diversos contextos, destaco las aportaciones desde la hermenéutica de Paul Ricoeur (1996); desde el pragmatismo, el trabajo de Hilary Putnam (2004); o de Enrique Dussel desde la teoría crítica latinoamericana (2001, p. 87-102).

18 Ellacuría señala una cierta síntesis o camino de encuentro desde la categoría de posibilidad, de lo que podría ser o realizarse para dar otra configuración efectiva a la realidad. Es importante "la categoría de 'lo que debe ser' como pista de lo que es posible. El 'debería ser' no es principio argumento de nada, sino poco más que un posible puramente formal. No puede presentarse un 'deber ser' ser actual si no es realmente posible. El 'deber ser' lejano tiene función de utopía; [mientras que] el 'deber ser' actual es el que se presenta como fuerza subjetiva real" (2009, p. 319). 
la propia praxis en la que acontece, como lugar de la verdad primera ${ }^{19}$, pero también como lucha por la realización de una verdad más plena, "La verdad [...] no es total hasta que muestre su capacidad operativa, su capacidad de hacer justicia” (ELLACURÍA, 1999, p. 25). Nos dice Ellacuría, "no podemos llegar a saber lo que es la humanidad y, en definitiva, el hombre, más que cuando acabe de ser históricamente todo lo que es capaz de dar de sí" (1991, p. 90.), y este dar de sí fuerza, a través de la propia praxis, la transformación de la realidad (ibid, p. 91).

Así, el ámbito desde el que se puede elaborar otro pensamiento y otro abordaje de las cuestiones prácticas con la pretensión de enfrentarse a la superación de esos reduccionismos será la historia aquí entendida no como un magno proceso en el que quedan desdibujados los sujetos pero como praxis histórica en la cual los sujetos no sólo son pacientes de los condicionamientos y fuerzas sino que son o pueden llegar a ser en un mayor grado agentes, actores y autores de su propia realización y de la realidad con la que hacen su vida.

La historia puede tragarse a las personas convirtiendo a éstas en puros números sometidos al juego de fuerzas que le son ajenas. Y no hay duda de que mucho de lo que se entiende por historia, mucho del curso de los acontecimientos, tiene un carácter a-personal. Pero es que entonces la historia ya no es historia, sino puro proceso natural, un proceso de naturalización, de despersonalización. Por lo tanto queda desprovista la persona humana y la historia misma de su peculiar sentido metafísico; si la persona humana queda absorbida en ese proceso, es porque ese proceso ha dejado de ser historia. Es algo posible. Pero aun en ese caso de naturalización de lo histórico, queda siempre, en virtud del incipiente carácter ab-soluto de la per-

\footnotetext{
19 En esta línea, resulta pertinente el abordaje de la praxis, desde una filosofía primera que lleva a cabo Antonio González a partir de una nueva radicalización fenomenológica del análisis de la acción humana realizada por X. Zubiri (1997, p. 11-43). Aquí, teniendo en cuenta esta perspectiva, tratamos de realizar un diálogo con ella a partir de la filosofía ellacuriana en la medida en que, a mi juicio, ofrece una visión complementaria y enriquecedora en la perspectiva de una filosofía segunda mediante enfoques y respuestas que no pueden obtenerse con la inmediatez que ofrece esta filosofía primera, pero que no por ello pueden dejarse de lado en una filosofía práctica para enfrentar los desafíos actuales.
} 
sona, abierta a la posibilidad de las posibilidades: el que el hombre puede volver a hacer historia y que en ese hacer histórico puede reconquistarse como persona (ELLACURÍA, 1975, p. 96).

Este hacer histórico, se articula en una cierta dialéctica entre libertad y necesidad. Construir socialmente la marcha de la historia humana, consiste en liberar la historia, en hacerse sujeto activo para darle otra dirección, y no meramente en ser sujeto paciente de los procesos históricos. Esta apertura de la historia, de cada sujeto, grupo humano, y en última instancia del conjunto de la humanidad, es la que permite la orientación de la praxis humana, la lucha por introducir una "novedad", por dar de sí una vida más plena y un mundo no roto ni dialécticamente enfrentado como dato definitivo.

El desenvolvimiento de la acción humana con lo real, consigo mismo, con los otros o con el mundo, nunca es meramente contemplativo, el ser humano "se da realmente en sociedad y en historia, como se da en naturaleza: se da en plena actividad, una actividad compleja, contemplativa y activa, que es de sí mismo y es de los otros" (ELLACURRÍA, 1975, p. 69.). También tiene un carácter activo y realizativo. Este modo de habérselas de la acción humana con las cosas en sentido lato, nos aboca a una tarea ética. Por ello, la verdad de la realidad, al entrar en juego la acción humana, y con ella la historia, no es simplemente lo dado o lo hecho, el factum, sino como nos diría Ellacuría, lo que está haciéndose y lo que está por hacer, es decir, la verdad tiene un carácter radicalmente histórico: "porque es el verum y sólo el verum el que ha de entenderse como un faciendum, pues sólo en esa realización, en ese darle realidad, puede hablarse plenariamente de verdad" (ELLACURÍA, 1975, p. 71). Es por tanto una tarea ética, una praxis, "pero esta praxis no es el cumplimiento de una obligación venida desde fuera sino la realización del propio dinamismo personal y del dinamismo social, que si son ambiguos, por lo tanto, pueden conducir tanto a la alienación de la sociedad como a la alienación de la persona, pueden llevar también a la realización plena de la persona en la comunidad" (ELLACURÍA, 1975, p. 71). Por tanto, en la realización abierta y responsable de esos dinamismos es donde se va a decidir la configuración que finalmente asuma la realidad humana. Y desde esta aper- 
tura y ambigüedad de los dinamismos humanos, se alzará la posibilidad ética de que la persona "se esfuerce creativamente por dar un sentido a la historia y por intentar la construcción de una realidad personal, social e histórica que permita la realización de ese sentido" (ELLACURÍA, 1975, p. 243).

¿Cuál es ese sentido de la vida o de la historia? Dice Franz Hinkelammert que el sentido de la vida es vivirla (2003, p. 369 et seq) Beorlegui., y podríamos seguir, que el sentido de la historia es hacerla. Creo que en última instancia tiene razón pues no es una simple tautología. O la vida y la historia merece ser vivida y realizada o nos caemos por el precipicio del nihilismo. Y en esta línea, cuando Ellacuría plantea el proceso histórico no como un mero proceso de hominización, o de mero despliegue biológico de la especie humana, sino también y principalmente como un proceso de humanización, está planteando el mismo problema; o también cuando plantea el problema radical de los derechos humanos como una lucha por la vida y en contra de aquello que produce muerte y negación. $\mathrm{O}$ bien la vida humana y la realización de la humanidad se afirma y libera sus mejores virtualidades o estamos abocados al fracaso. La vida debe ser vida digna y no vida negada, y la historia, hecha por la personas, por el conjunto de la humanidad en última instancia, y no padecida como un proceso que nos arrastra, amenaza y cosifica. Es decir, o vivimos una vida con sentido, y una historia con sentido, o no tiene sentido vivirla ni hacerla.

Pero ello, no nos lanza a un abandono rápido de la vida o de la historia, ni a un suicidio individual ni colectivo. No es aquello de "que se pare el mundo que yo me bajo". Nos invita, si queremos hacernos cargo de la densidad de lo real y de sus posibilidades, a no dejarnos engañar por las apariencias de lo que hay como lo definitivo; de la ruptura y la enemistad como el último dato de lo humano; a una rebeldía contra el mal sufrido y la alienación; a una rebeldía por la vida y la solidaridad en contra de la muerte inflingida y la negatividad ${ }^{20}$. No a la espera, sino a la esperanza activa de los que construyen y hacen irrumpir otro futuro en

\footnotetext{
20 "Heidegger pensaba (Was ist Metaphysik?) que era la nada la que fundamentaba la posibilidad del no y, en general, de la negatividad; por ello, quizá, en vez de preguntarse por qué hay más bien ente que nada, debería haberse preguntado por qué hay nada -no ser, no realidad, no verdad, etc.- en vez de ente". (ELLACURÍA, 1985, p. 101).
} 
medio del presente. Siempre en la facticidad hay un "más" que sólo se ve o desarrolla por la esperanza que anima la profecía y la utopía: "profetismo utópico que desde la negación anuncia un futuro mejor y concreta los modos de su realización” (ELLACURÍA, 2001, p. 439).

Esta lucha por la vida y por abrir sus posibilidades, puede adquirir la forma de lucha por los derechos humanos, y esto, permite fecundar el campo jurídico (campo de la ambivalencia por excelencia, pues es administración de la vida y de la muerte) y darle otro "sentido" histórico con el proceso de realización de los ideales éticos que están presentes en las luchas por los derechos humanos. Como apunta Ellacuría en su análisis, el "deber ser" o la exigencia está ya dada de algún modo en la propia vida negada que se experimenta como invivible y que pide su superación. La conciencia de esta situación permite abrir la lucha por hacerla vivible o digna, es decir, por la negación superadora de la situación de opresión, pero también obliga a un cierto ejercicio racional y ético de construcción normativa, que se articula en diversas tradiciones culturales, por construir un mundo donde los otros también puedan vivir.

Desde este horizonte de comprensión de las prácticas normativas, se muestra también la necesidad de superar un enfoque de los problemas jurídicos que se concentre únicamente en los problemas lógicos o de no contradicción formal entre sus diferentes piezas, de coherencia axiológica, y no contemple los sistemas jurídicos como universos autorreferenciales y autosostenidos ${ }^{21}$, que flotan en sí mismos con una pretensión de

21 Es sumamente interesante recoger la aguda crítica de Ortega y Gasset, quien es uno de los precursores intelectuales de este horizonte de la praxis histórica como lugar adecuado de intelección de los fenómenos humanos y sociales, a las derivas idealistas que se producen en la primera mitad del siglo XX en la teoría jurídica más influyente, tanto por parte del neokantismo como del positivismo formalista: "El derecho no se funda últimamente en algo, a su vez, jurídico, como pretendía la extravagancia de Kelsen, extravagancia oriunda de haber entendido mal a mi maestro de Marburgo, como ya lo entendió mal Stammler (...) La teoría del derecho de Kelsen, de que se han empapuzado los juristas y filósofos del derecho de todo el mundo, sólo podía terminar donde ha terminado con una palinodia. El derecho-digo- no se funda en algo, a su vez, jurídico, como la ciencia no se funda últimamente en nada científico, sino que ambos se fundan, cuando los hay, en cierta situación total de la vida humana colectiva" (1983, v. 9, p. 144, subrayado mío). 
suficiencia que le permite incurrir con aparente tranquilidad, en su caso, en el despotismo de la ley: "el derecho de un Estado no es un ideal, sino algo que existe efectivamente (...) no es lo que debe ser sino lo que es" (GRAY, 1948, p. 213 apud HART, 1998, p 256). En esta línea, el derecho puede transitoriamente tener "cualquier contenido", salvados los problemas lógicos, como quizá se pueda sostener desde el formalismo kelseniano ["Las normas jurídicas pueden tener cualquier tipo de contenido" (KELSEN, 1945, p. 113 apud HART, 1998, p. 256)] al consistir el derecho en pura formalidad. Lo cual en un cierto sentido puede darse provisionalmente en el peor de los casos. Herbert Hart, sostenía más realista y prácticamente, y en esta línea participaría de este horizonte de la praxis, que si el derecho no quería convertirse en "reglas para un club de suicidas", tenía que tener ciertos contenidos mínimos que protegieran la vida de los actores para poder seguir operando en el futuro: "dada la supervivencia como objetivo, el derecho y la moral deben incluir un contenido específico" (1998, p. 239. subrayado mío). "Dada la supervivencia como objetivo", implica que no hay garantía ni lógica ni metafísica de que eso se dé y por eso un sistema de prácticas normativas puede consistir aún de forma muy transitoria en "reglas para un club de suicidas". Por ello, el objetivo es puesto por los actores de un sistema normativo; de ahí que sea en la tarea normativa como tarea ética en toda su amplitud, donde se juegue tanto el futuro de la realidad como el de la propia praxis y por tanto ésta va cargada de densidad, pues en ella se está decidiendo desde sí misma y con sus propias actuaciones, tanto la posibilidad de la racionalidad $^{22}$ como la de la realidad humana que no son instancias que se pueden dar por seguras sino que hay que sostener y realizar, si queremos seguir viviendo, como emplazamientos de nuestras propias acciones y no sólo como dimensiones o momentos de las mismas. A su vez, al señalar la necesidad de conseguir alcanzar ciertos contenidos, estaba planteando de forma incoativa, el problema de ajuste o desajuste de las prácticas norma-

\footnotetext{
22 Señala Ellacuría que quien "hace verdaderamente racional la historia es quien introduce en ella proceso racionales, no sólo en cuanto se acomodan a una realidad dada y la hacen "funcionar" mejor sino en cuanto introducen procesos y dinamismos en relación a un deber ser" (2009, p. 319).
} 
tivas y su función en las vidas humanas como sistemas psicobiológicos de acciones sostenidos en el tiempo que necesitan hacerse viables.

Desde este marco, hay que entender dinámicamente el problema del ajuste o desajuste.

\section{El Ajuste y otras Dimensiones de las Prácticas}

Antes de entrar en la significación del ajuste y sus implicaciones en el despliegue de las prácticas normativas conforme a derechos humanos, lo situaremos brevemente en el conjunto de dimensiones normativas.

Indicaba Ellacuría que el problema de los derechos humanos hay que plantearlo desde un triple plano: "en lo que tiene de verdadero y falso -problema epistemológico-, en lo que de justo e injusto -problema ético-, y en lo que tiene de ajustado o desajustado -problema práxico o político-" (Ellacuría, 2001, p. 434). Entre los tres momentos, se articula una "unidad estructural" como momentos determinantes de algo o que se codeterminan, pues tienen una refluencia sistemática en el conjunto. El "sistema", lo es por sus notas constitutivas y la mutua acción de unas sobre otras, de modo que cuando no alcanza o una de sus notas no se da ya, adquiere otra configuración y es otra cosa. Por ejemplo, un derecho, no es "derecho humano" cuando pierde la vocación de universalidad, se limita a ser derecho de grupo que se construye sobre la exclusión de otros y se convierte entonces, en "privilegio". Aquí hay una opción teórica radical que busca integrar lo que en la realidad se presenta como internamente vinculado aunque sea de modo sui generis, de esta manera, lo que sea un verdadero derecho humano, debe ser lo justamente debido a toda persona en cuanto tal o en su concreta especificación por responder a una exigencia radical, y a su vez, su realización, o su realizabilidad muestra lo ajustado o desajustado de lo que presenta como verdadero y justo derecho ${ }^{23}$.

23 En este sentido, habría que decir que no cabe una "justeza injusta", pues la justeza es la dimensión práctico-real de la justicia. $\mathrm{O}$ dicho de otro modo, un ajuste injusto, como podría ser el caso del gansteril "ajuste de cuentas", elimina las exigencias de la justicia en el ajustamiento, y en este sentido, mantiene un carácter desajustado visible en el resultado de las muertes. 
Pero esta dimensión práxica ha de entenderse como algo abierto, ya que la praxis humana no está cerrada conforme a cada una de las concretas situaciones fácticas y puede siempre haber una lucha por su superación; por ello no se puede reconocer sin más que lo verdaderamente debido es lo que aparece como realizable según unas concretas condiciones actuales, sino que lo verdaderamente exigible en orden a su actualización sea el ir abriendo históricamente las posibilidades reales conforme a lo que se presentan como exigencias humanas que deben ser atendidas en la propia realización histórica de la sociedad humana. Dicho de otra manera, si el momento práxico nos ofrece un realismo que pone al descubierto lo que ocurre con los ideales humanos, y a su vez, cómo estos pueden ser empleados ideologizadamente, en nombre de este "realismo" no se puede negar el carácter real de la apertura de la historia humana a su plenificación mediante la realización de lo que es debido a las personas en cada momento o situación. En este contexto, hay que señalar que estos tres momentos son en última instancia criterios utópicos que pueden orientar este tipo de prácticas.

\section{Implicaciones de los Usos del "Ajuste, Ajustamiento o Justeza"}

Ellacuría nos habla de "ajuste, ajustamiento o justeza" como sinónimos, y de sus contrarios. Vamos a considerar los usos posibles de esos términos y su empleo filosófico. En un primer sentido, nos dice la RAE, que justeza o justedad es la condición de justicia. No es ese el sentido en que se usa en el análisis ellacuriano, pues entonces no aportaría nada a la delimitación de lo justo. La cualidad de la justeza o justedad apunta a otro sentido complementario a la idea de justicia. Según la RAE, justeza o justedad es "2. Igualdad o correspondencia justa y exacta de una cosa". A ello, añade el Diccionario de María Moliner: "correspondencia exacta de una cosa con otra". Lo que le es debido o le corresponde a una cosa, está implicado en su relación con otra. Por tanto, apunta a una dimensión relacional y contextual de la justicia, no puramente normativa o ideal de la misma. Con la idea de justicia, Ellacuría resalta en un primer término el momento de idealidad, de exigencia racional o de normatividad ética (Ellacuría, 2001, p. 434); con el de justeza, la funcionalidad práctica y 
real de esa normatividad y por tanto la devolución de la corrección material de la concreción racional.

Es cierto que desde Aristóteles se viene considerando la justicia como la virtud social por excelencia. En este sentido, es el criterio ético de orientación y ordenación de las relaciones sociales. Según Aristóteles la justicia es la "virtud completa", pues "no es una virtud absoluta y puramente individual; es relativa a un tercero (...) La justicia parece ser entre todas las demás virtudes, la única que constituye un bien extraño, un bien para los demás, y no para sí" (1982, v1). Así, se resalta con fuerza el dinamismo externalizante o universalizador de una razón bien ejercida que busca la corrección más allá de uno mismo. Ahora bien, como el propio Aristóteles apunta, la concreción racional de lo justo en una situación tiene también sus riesgos y sus peligros en los diversos contextos y regímenes. Baste con la observación inveterada de que no se es buen juez en causa propia. Y continuamente nos encontramos, no con la consecución del "bien para los demás" y de la razón bien ejercida en los procesos de institucionalización normativa, sino con el mal y el error, como pretende mostrar en su Política. Es decir, con la injusticia. Si la justicia, en un sentido omnicomprensivo (plano epistemológico, ético y práxico (1982, epígrafe 3) es la correcta articulación entre razón y bien, entre verdaderos ideales y materialidad plenificante (vida buena para todos); la injusticia sería la presencia del error y del mal, de falsos ideales y de destrucción o fracaso de la vida.

Por ello, a pesar de tener una referencia social como término, el concreto ideal de justicia que se articula en una situación puede quedarse a mitad de camino y pretender dar por justo lo que sólo lo es muy parcialmente, de ahí que no baste la concreción y reclamación o institucionalización de un cierto ideal, pues este se puede quedar en una concepción limitada o no "completa". Es decir, es el paso por lo real, su dar de sí ante la realidad de los otros, lo que llega a mostrar la auténtica cara del ideal pretendido. Por tanto es su principio de verificación (ROSILLO, 2009, p. 169).

En esta línea, entiendo que hay que situar el problema de la justeza o no justeza, del ajuste o desajuste. Entonces la justeza aparece como una instancia que sirve de elemento crítico y objetivante a la concreción de la 
idea de justicia y de sus "grados" en función de la configuración en que deje o permita estar a los otros, lo cual libera la búsqueda y la realización de una justicia siempre mayor.

Si no se trata de reconocer sólo la exigencia de un ideal que se plantea como racional, sino que hay que verificar prácticamente su pretendida virtualidad, entonces hay que buscar un criterio de lectura de la praxis, de su dar de sí social e histórico. Y ese criterio desde la praxis lo señala Ellacuría desde la categoría de justeza, que aún teniendo la misma raíz que justicia, es como su despliegue en la realidad. Por ello, conecta la justeza con el ajuste o ajustamiento, como expresiones equivalentes o intercambiables $^{24}$.

Si traemos la etimología y los usos habituales, ello nos puede dar algunas ideas sobre sus implicaciones. Nos dice el Diccionario de la RAE, seleccionando algunos de ellos: “Ajustar, del latín ad, a, y iustus, tr. 1. Hacer y poner alguna cosa de modo que case y venga justo con otra. 2 . Conformar, acomodar una cosa a otra, de suerte que no haya discrepancia entre ellas. 3. Apretar una cosa de suerte que sus varias partes casen o vengan justo con otra o entre sí. 4. Arreglar, moderar. 5. Concertar, concordar alguna cosa como la paz, las diferencias o los pleitos. 6. Componer o reconciliar a los discordes o enemistados [...]" (RAE, 1992).

Así pues, la cualidad de justo está aquí connotada adverbialmente en el "hacia", o en el "junto a", que rompe el riesgo autorreferencial de una justicia que se pueda quedar en la pura abstracción y con ello permanezca autocentrada. Esta dimensión relacional y transitiva pero con sentidos también intransitivos, como acción que modula algo o que refluye sobre uno mismo, está articulada espacial y materialmente, pero también, y montado sobre lo anterior, humana y socialmente. Ello le hace desplegar los diversos sentidos del ajuste o ajustamiento.

24 Lo cual no es a su vez sino una continuación a su modo de la filosofía de Zubiri, quien también conecta la justeza con el ajustamiento (en un sentido que veremos en el siguiente apartado): "el carácter de la adecuación del animal está expresado en un solo concepto: el ajustamiento, el ajustamiento entre el animal y su medio. El carácter formal de esta propiedad la llamaré justeza" (1986, p. 346). 
El ajuste, en primer término, se articula tanto en el ajuste entre las cosas, (co-existencia posible y ordenada) como en el ajuste inter-humano, que implica los sentidos del ajuste entre las cosas, de la coexistencia material, pero también avanza hacia otras dimensiones nuevas en la con-vivencia. Vivir con otros, implica moderarse o autolimitarse para que los otros también puedan ser y vivir en un sentido físico y material y también vivir gracias a la acción solidaria de los otros (bienes o recursos materiales sujetos a la dinámica del bien común); pero también implica exigencias racionales de reconocimiento de los otros y también de consenso o acuerdo de facto en el mutuo reconocimiento, como los tratados o acuerdos legales.

Si no nos deslizamos por el peligro reduccionista del consenso o de las meras exigencias racionales, se ve a las claras una instancia material desde la filosofía ellacuriana, ya que el consenso o la racionalidad, aunque ideológicamente no lo tengan en cuenta, siempre se enfrentan a un límite crítico exterior al mismo, por aquellos que son excluidos de la posibilidad de seguir viviendo o están sometidos a un malvivir. ¿En qué sentidos se expresa? Podríamos decir por ahora al menos los siguientes sentidos: en un sentido espacial (los excluidos del territorio), físico (los aniquilados por la administración de la muerte legal), temporal (las generaciones futuras cuyo futuro puede cerrarse o imposibilitarse), social (grupos subalternos), económico (los pobres), político (los excluidos de los derechos políticos o los declarados enemigos) o cultural (tradiciones minorizadas y colonizadas), entre otras instancias posibles.

Después de visto los usos o sentidos en una primera aproximación lingüística y filosófica que se expresa en la dimensión del ajuste, vamos a ver brevemente esta cuestión desde la primordialidad de la praxis.

\section{El Ajustamiento de la Acción Humana: el ajustamiento para ser viable}

Cuando adopta una respuesta, el ser humano no sólo tiene que dar razón de la respuesta ante sí mismo o los demás (es decir, justificarla), sino que además, en última instancia, si quiere seguir viviendo o dan- 
do respuestas, éstas tienen que ser "ajustadas" en un sentido biológico o material. Es decir, que lo real (él mismo, los otros, o la naturaleza), le devuelva de algún modo no sólo la corrección formal (justicia), sino la corrección material (justeza, ajustamiento) en forma de subsistencia o continuidad del actor ${ }^{25}$ por su equilibrio con el contexto material, lo cual es una exigencia de la acción humana para ser factible. En esta línea, Ellacuría toma de la filosofía de Zubiri (1986, p. 343 et seq) no un principio de vida como un presupuesto fuera de la praxis, sino que desde la misma praxis plantea el problema de la vida en su dimensión de ajustamiento de la acción para poder seguir actuando y configurándose.

¿Cómo es este ajustamiento? En la acción del animal con su medio natural se da un cierto ajustamiento dado desde sus propias estructuras. En realidad, no tiene que interpretarse como un automatismo con éxito, sino en el sentido en que el modo de habérselas del animal con su medio está prefigurado por un sistema de respuestas propio de su especie, de modo que el "individuo" o cada generación no tiene que inventarlas sino que le vienen dadas y que le asegura, si las condiciones no cambian, un cierto éxito en forma de continuidad de la vida propia o de la especie. De hecho, cuando cambian las condiciones del medio natural y el sistema de respuestas biológicas de cada especie no es eficiente para asegurar una cierta sobrevivencia de los individuos de la especie, ésta desaparece.

En el caso de la acción humana, al entrar en juego la inteligencia, y con ella la apertura de las respuestas humanas frente a sí mismo, el medio o los otros, entra también en juego toda la creatividad y variabilidad propia de lo humano, frente a la repetición o continuidad de los esquemas comportamentales de los animales. Pero la necesidad de asegurar y asegurarse el "ajustamiento para ser viable" como ser vivo subsiste en la persona al igual que en el resto de seres vivos. Y para ello, tiene que alcanzar el ajustamiento para ser viable en un cierto equilibrio entre el medio, los otros y el propio ser vivo. Pero la consecución de este ajustamiento equilibrado no le está dado de antemano como un esquema conductual pre-

25 Dicho sea de paso, si queremos seguir viviendo, necesitamos una instancia última, que de algún modo sane nuestra contingencia, pues finalmente no confrontamos con la muerte que vence, aun cuando toda nuestra vida sea una batalla contra la muerte rápida o la muerte definitiva, es decir, una instancia que sea posibilitante en un sentido radical. 
figurado biológicamente. Como señala Zubiri, la respuesta a dar es inespecífica dado el modo o habitud en que intelige, por lo que tiene que dar el rodeo por la irrealidad para responder: "considerar la realidad antes de ejecutar el acto es, por lo pronto, moverse en la pura irrealidad. Con lo que queda indeterminada la figura del ajustamiento humano. Por eso el hombre tiene una historia prácticamente indeterminada, cosa que no le acontece al animal que vive constitutivamente enclasado" (1986, p. 343 et seq).

Así, con la inteligencia entra en juego toda la creatividad cultural que está enmarcada en la necesidad de articular con éxito el ajustamiento entre los miembros de la especie humana y de esta con el conjunto de la naturaleza, para asegurar la vida de los miembros de la especie y la continuidad de la misma. Con la aparición de la inteligencia como novedad en el orden cosmológico, se "supera" o se hace inviable el modo de responder puramente animal, su ajustamiento al medio y a la propia especie, no puede darse como en el resto de seres vivos, no puede sencillamente continuar por medios puramente biológicos.

Por ello, es inexorable la liberación de la dimensión ética. De ahí que la sociedad humana no pueda hacerse cargo de las exigencias biológicas "naturalmente", es decir, en virtud de una "legalidad" o sistema de respuestas inscritas en su mera estructura biológica, o en las palabras de Ellacuría "el hombre como individuo y como especie no serían viables biológicamente si su realidad animal no 'liberara' una dimensión ética" (1979, p. 255).

Pero esta dimensión ética no garantiza el éxito ni en la respuesta ni en su resultado sino que tiene ir construyendo, inventando y probando este ajustamiento para ser viable. Si bien, sigue inmerso en situaciones como el resto de los animales, y está “"sujeto-a' todo aquello que las situaciones les exigen. Esta es la base común de la que arrancan diferentes procesos: la inmersión en la naturaleza, la sujeción-a los múltiples avatares, a los que se ve sometida la vida biológica [...]. Pero el hombre 'supera' esta inmersión natural de otra forma, porque forzosamente ha de resolver estas situaciones por decisión. Y esto es así, porque el hombre, en virtud de su apertura a la realidad, responde a las necesidades de la naturaleza, mediante la interposición de posibilidades" (1979, p. 256). 
Por ello, este modo de ajustamiento humano, tiene un alto grado de problematismo, su ajustamiento como hemos visto es inespecífico, no sabe de antemano cómo actuar, pero el emplazamiento sigue siendo el mismo, responder con éxito ante su medio para poder seguir subsistiendo, en última instancia, también como especie. En este camino para alcanzar el ajustamiento, tiene que "hacer el trazado de su ajustamiento", dar el rodeo por la irrealidad, interponer posibilidades y hacer una y otra vez todo el camino ético. Pero siempre tendrá que ir no sólo justificando lo que se va haciendo, no sólo "dar razón de la razón" de la elección, sino que tendrá que irse ajustando materialmente por medio de la propia tarea ética para irse desenvolviendo, como sujetos y sociedad en la realidad en que se encuentran situados. El primer significado de los derechos humanos que Ellacuría propone es el siguiente: "son una necesidad de la convivencia social y política; son una necesidad socio-biológica y político-biológica, sin la que se hace inviable la especie y el modo social y político, en que la especie humana debe desenvolverse" (1989, p. 430). Alcanzar las respuestas adecuadas a este emplazamiento, a esta necesidad, es una tarea para la que no basta la mera justificación del decurso social en términos racionales o ideológicos, sino que su misma corrección se va decantando desde su funcionalidad en el mundo y por la viabilidad que ofrecen. Ello se va revelando desde la propia experiencia o en la "probación de realidad" de esas respuestas, de esos esquemas comportamentales que son concreciones normativas o institucionales que articulan el trato con uno mismo, con los otros y con la naturaleza en los diferentes subsistemas prácticos.

Entre el no ajustamiento de partida y las exigencias de la realidad, se articula el enorme campo de posibilidades que se experimentan en la marcha histórica de la humanidad. Al haberse unificado la historia para todos los grupos humanos, ya el ajustamiento de cada grupo social no depende sólo de sus propias prácticas, sino del conjunto de prácticas normativas de la humanidad en su interacción humana y natural, que es lo que determina la propia viabilidad o no de la propia humanidad y de los grupos que la conforman.

Una praxis ajustada es una praxis que posibilita la continuidad de la realización. Una praxis desajustada es aquella que está imposibilitando la continuidad de la realización, en último término, de la propia humanidad. 
¿Será nuestra praxis una praxis de "idiotas" o una adecuada a las exigencias de la realidad? Nos dice Zubiri, que "la primera y elemental función de la inteligencia será de orden puramente biológico: habérselas con las cosas como realidad, pues sólo así el animal humano es viable biológicamente. Una serie de hombres que fueran constitutivamente idiotas formarían una especie inviable" (1986, p. 346) ${ }^{26}$. Pero aquí "realidad" no es sólo una formalidad en que se actualizan las cosas y las acciones, sino la realidad allende los actos que es la que condiciona la viabilidad de los sujetos.

Aquí se abre, no sólo una lucha por la razón en contra del error, sino por la vida despojada y contra las aparentes razones de los fuertes que producen la pauperización y el fracaso para otros, pero en último término también para su propia humanidad, pues no hay justicia sino como "virtud completa", como vida buena para todos o desde el bien común. Es la lucha por los derechos humanos como proceso.

\section{El Ajuste o Desajuste en el Proceso de Lucha por los Derechos Humanos}

Siguiendo la observación epistemológica de Ellacuría,

El despliegue de la realidad no sólo alcanza en la historia su momento último, sino que el discurrir histórico va desvelando y revelando la verdad de la realidad. Una realidad que, por muchos capítulos, es un escándalo a la razón ahistórica, que estimaría como irreales muchas de las estructuras y muchos de los sucesos históricos. La identificación del ser con lo bueno y lo verdadero a una razón que se ha erigido en medida de todas las cosas, choca con la realidad histórica del mal y del error. Lo cual trae consigo necesariamente la dialéctica en el plano teórico y de la praxis revolucionaria en el plano de la acción. La historia era sacada antes del ámbito de la ciencia y de la metafísica, porque su aparente contingenciali-

26 En esta línea hay que situar la constatación zubiriana, al final de su trilogía sobre la inteligencia, de que "el gran problema humano [es] saber estar en la realidad" (1983, p. 352). 
dad no casaba con la aparente y superficial permanencia y universalidad de la realidad. Aquí se propone retrotraerla al núcleo mismo de la ciencia y de la metafísica, porque si se toma en su propia realidad concreta y no sólo en lo que tiene de diferenciativo es el gran criterio de verdad, de revelación de lo que es la realidad. Porque de revelación se trata y no meramente de desvelación, pues la realidad misma se realiza y no meramente se despliega o se desvela y la praxis histórica fuerza la realidad para que se transforme y manifieste (ELLACURÍA, 1991, p. 91),

la verdad de algo, no simplemente se desvela, como lo que está oculto y se hace presente, sino que se revela. Es la presencia de la negatividad, la situación de desajuste, el principio de lo revelado. Es la presencia del conflicto que se expresa como relación dialéctica con otros, en forma de vida imposibilitada, que no puede llegar a ser lo que podría porque se lo impiden, la que permite cuestionar el esquema normativo que rige una situación social como insuficiente, no completo y por tanto "no-justo". Pero es la no conformidad o rebeldía con ese estado de cosas, el principio revelante y ello apunta a la consecución de una cierta positividad, por ejemplo en forma de vida digna. Esta resistencia o no conformidad es la que desde la praxis fuerza la transformación de lo dado para alcanzar otra realización mejor, y por tanto, una verdad más plena. Aquí es donde entiendo que se conecta el ajustamiento de la acción humana, que es una tarea continua en tanto que siempre puede subsistir alguna forma de desajuste, con el proceso de lucha por los derechos humanos.

Desde esta situación de desajuste de partida, puede haber un dinamismo de superación, que no se queda el dato del desajuste sentido, sino que avanza hacia una cierta positividad. ¿Cómo se articulan ambos planos? Dicho zubirianamente, por el rodeo por la irrealidad. Esto permite la interposición de un proyecto que es otra idea de lo que puede ser, de otra posibilidad, que antes de ser apropiada personal, grupal o socialmente, es irreal (aunque podría ser real), pero una vez conquistada, permite dar otra definición efectiva de su propia realidad, una forma de vida que responde a otra idea de lo que debe ser cada situación vital. 
Este rodeo por la irrealidad para dar de sí otra situación, no es puramente "a-real", y se mueve en un proceso dialéctico ${ }^{27}$. Se trata de descubrir, primero en un plano intelectivo, y desde una situación histórica, no una posibilidad puramente fantaseada y extraña, sino "cuál es el rostro histórico del derecho deseable y posible" (2001, p. 438). Esta proyección, que es lectura de la realidad y de una alternativa concretizable o un "deber ser actual", se convierte en pro-yecto, en aquello que es "lanzado" a la realidad desde una actividad humana: en la lucha por la realización del derecho. Pero la realización, no es sólo pasar de la irrealidad a la realidad, sino de una realidad casi anonadada, a una realidad más plena, el paso de una negación a un "disfrute" 28 . Se trata de lograr "que la lucha por la realización del derecho consiga que se haga justicia y llegue a anular, no necesariamente a aniquilar, la realidad negadora en lo que tiene de negadora" (2001, p. 438). La anulación de la fuente del malestar, no tiene que, o no debiera, traducirse en otra negación para otros, en aniquilación. Aunque eso se dé, no es propiamente parte del dinamismo de superación. Hacer justicia a unos, como históricamente se ha hecho tantas veces, ha sido ajusticiando a otros ${ }^{29}$. Pero, en su caso, esa nueva negatividad infringida muestra, a su vez, un nuevo desajuste por el carácter limitado y no completo del derecho conquistado o de la situación justa disfrutada.

En este sentido, en el proceso de ajuste, se da una interacción entre el momento ideal o utópico y el momento real de negación concreta: se

27 Dice Ellacuría que su "dialecticidad" se da en juego de teoría y praxis. En realidad, está concibiendo esta "teoría" como un momento de la praxis, y no desde una presunta ajenidad de ambos planos, en esta clave, se mueven los dos trabajos de Ellacuría inéditos recogidos en Actas del Congreso Internacional Ignacio Ellacuría 20 años después, "Dimensión ética de la filosofía" y "Perspectiva histórico-ética de la filosofía latinoamericana".

28 Los derechos humanos, si son tales en verdad, tienen no sólo una formalidad de reconocimiento, sino un "disfrute", que es no sólo posibilidad de realización efectiva, sino un momento fruitivo y felicitante para la persona. Ello enmarca los derechos no sólo en un plano puramente de actividad sobre la realidad, sino actividad de un ser humano sobre su propia realidad.

29 O incluso en su caso a la propia naturaleza, quien ha sido imputada en la tradición moderna como una fuente de crímenes para la humanidad, tal y como señala John Stuart Mill en su obra On nature, de ahí el imperativo del irrespeto a la naturaleza o a sus formas de vidas no humanas, para hacer justicia a la humanidad (SENENT, 2009, p. 179-182). 
trata de un proceso negativo, crítico y dialéctico, que "busca no quedarse en la negación, sino que avanza hacia una afirmación nunca definitiva" (ELLACURÍA, 2001, p. 436). En todo proceso personal y social, siempre subsiste el "elemento de desajuste, injusticia y falsedad" (ELLACURÍA, 2001, p.436). Pero no de la misma forma. Si se está en un proceso activo de superación y no de simple reproducción del malestar, se está desplegando una dinámica de lucha. La lucha, cuando se da, es lo que

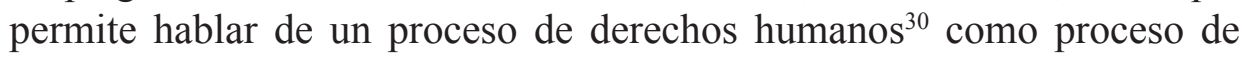
liberación que puede ser realizado históricamente. Se mueve en la conquista de algo alcanzable y positivo pero a su vez limitado, ya que nunca agota o cumple la realización de lo que debe ser en la teoría ideal completa: "lo verdadero, lo justo y lo ajustado"31. Es la tensión permanente entre el ideal utópico y lo vivido lo que puede abrir y continuar en cualquier momento el proceso. Esta idealidad no es simple "teoría" hecha, aunque pueda ser realizada al tematizar un aspecto del ideal, sino propiamente un más inespecífico que es un momento de la praxis humana, que puede ser concretado en una elaboración teórica o en una construcción ideológica, como históricamente se da, lo cual puede ayudar a dinamizar socialmente la formulación y consecución de ese "más". No hay una escisión socio-teórica entre lucha de liberación e ideales utópicos, entre "sabios y vulgo"; por ello puede ser lanzada por cualquier grupo humano, aunque tampoco incomunicación radical entre formulaciones teóricas e ideologías sociales y prácticas de grupos, sino complementariedad como momentos distintos de la praxis social ${ }^{32}$. En tanto que esto sea así, también hay consecuencias decisivas para el orden jurídico y político de una sociedad, pues tampoco

\footnotetext{
30 Cf. Weber (1985)

31 Ibid.

32 Por ello, Ellacuría, aun cuando suela hablar de "teoría y praxis", concibe el momento teórico en el seno de la praxis social, para bien o para mal, y por tanto ni hay ajenidad, ni hay creación del mundo social por el pensamiento, sino corresponsabilidad en el conjunto de la praxis, bien o mal ejercida. Desde ahí, creo que pueden entenderse sus textos en este volumen. Pero no todas las teorías ni las ideologías ayudan a un correcto discernimiento y desenvolvimiento adecuado de la praxis social, aunque puedan contener elementos valiosos para la misma. En este sentido, es la propia praxis social el lugar para esclarecer la verdad y funcionalidad de esos aspectos. Igualmente, ni la teoría ni la ideología agotan la praxis social que siempre es más que esos momentos.
} 
hay una escisión o fractura socio-jurídica en el proceso de lucha por ideales o por los derechos humanos entre institución, sea esta legal o política, y prácticas sociales instituyentes. Incluso cuando el momento de institucionalización jurídica y política de estos ideales concretados en las prácticas sociales sea un referente ineludible, esta institucionalización no agota ni cierra la lucha por los derechos humanos, pues no hay ningún cierre dogmático eficaz de la historia; aun cuando desde el poder instituido se pretenda detentar el monopolio social del saber, de la voluntad o del poder, pero en tanto subsiste la praxis viva de la sociedad, y en función de sus contradicciones y anhelos, siempre puede abrirse la posibilidad de otro proceso instituyente global o de la consecución de un elemento valioso parcial negado en un momento dado para una sociedad, grupo o persona, $\mathrm{u}$ otra alteridad con la que tiene que habérselas la praxis humana.

Por ello, señala Ellacuría que la "violación de los derechos humanos (...) [es] motor de la lucha por ellos". Pero esta violación o negatividad es "fundamento y principio de los derechos humanos". Si esto es así, no hay desde la filosofía ellacuriana ni escisión socio-teórica ni socio-institucional al radicarse en la propia praxis. ¿Ello no implicaría una cierta contradicción en sus términos? Al considerar la praxis en su complejidad se puede salir de una aparente e inicial contradicción. Se da aquí una relación entre utopía y denuncia que mutuamente se potencian. Como señala, "sin una cierta apreciación, al menos atemática de un ideal utópico, que es posible y exigible, no puede darse la toma de conciencia de que algo puede ser superado; pero sin la constatación efectiva, cuyo origen puede ser múltiple y complejo en el orden biológico, psicológico, ético, social, cultural, político, etc., de que se da una negación, que es privación y violación, la toma de conciencia no se convierte en exigencia real y en dinamismo de lucha. La denuncia sin utopía es, hasta cierto punto ciega, pero la utopía sin denuncia es prácticamente inoperante"33.

33 ELLACURÍA, 2001. 


\section{Bien Común, Mal Común y Factibilidad}

Al hilo de este análisis, podemos preguntarnos cuál es el ideal utópico que mueve hoy las prácticas sociales críticas. En el conjunto de la negatividad sentida por muchos grupos sociales de la humanidad, yo diría que las actuales praxis críticas e instituyentes animadoras de otra construcción histórica convergen en una cierta orientación utópica. Se orientan por un criterio utópico de justicia entendida como bien común humano universal, donde también se dé y articule un cierto bien común de la naturaleza en el que se desenvuelven las prácticas de la propia humanidad. Las luchas sociales contra la exclusión social están cada vez más conectadas con otras luchas sociales contra la destrucción de la naturaleza. El proceso de unificación fáctica y su consiguiente crecimiento en interdependencia entre las condiciones de vida humana y no humana hacen convergente el bien o mal humano con el bien o mal ecológico.

El momento de denuncia que sirve para perseguir ese criterio utópico de justicia es la experiencia del mal común, que es lo que se da de hecho para muchos grupos humanos (ELLACURÍA, 1989) que no pueden sostener una existencia social satisfactoria en tanto están mal afectados por estructuraciones sociales que impiden su propio y correcto desenvolvimiento personal y grupal. Pero a su vez, hoy, esa experiencia del mal común humano, se ve agravada por la negatividad que para las condiciones sociales de vida, e incluso sobre sus propias vidas en un sentido biológico, tiene el mal común ecológico. El proceso de destrucción de la naturaleza que en la presente fase histórica se está realizando también está socavando las propias condiciones de vida humana, y hasta las propias vidas humanas, exigiendo que el ideal utópico sea la superación de esa negatividad vivida. De este modo, el proceso de abuso de los recursos naturales y de alteración de los ciclos naturales que está generando la actividad humana, produce ya una visible injusticia social para ciertos grupos, que no se benefician de ese proceso destructivo sino que sufren sus consecuencias más directamente, y a su vez, está poniendo en riesgo de colapso la continuidad del conjunto de la actividad humana en el planeta. Esta negatividad sentida, y conocida cada vez mejor, demanda la reorientación del criterio hacia un criterio utópico de justicia interhuma- 
na incluyente y también descentrada, que incluya la justicia ecológica o ambiental. Si queremos seguir viviendo y no solo empobreciendo nuestra especie, sino acrecentando nuestra humanidad, tenemos que orientarnos por el bien común humano universal donde también se integre el bien de la naturaleza en la que se desenvuelve la existencia humana.

Esta lucha por la vida presente de toda la humanidad y de su futuro en el conjunto de la naturaleza, implica desde el criterio de justeza la búsqueda de la factibilidad ecológica o la sostenibilidad natural de la vida humana en el conjunto de la naturaleza ${ }^{34}$. Por ello, los ideales utópicos que quieren ampliar y plenificar la existencia humana hoy, no están desconectados de otras exigencias de la realidad, dadas las otras alteridades en las que se desenvuelve la praxis humana, incluida la propia corporalidad. Estas exigencias, se pueden formular humanamente como deberes ante la naturaleza (Senent, 2009, p. 699-708), o incluso como derechos de la misma, toda vez que la propia praxis humana puede reconocer otras fuentes de deberes o derechos no sólo interhumanos.

El ideal de justeza, cualifica el criterio utópico de justicia de un mundo donde quepan todos y tengan vida digna viable o sostenible. La justeza implica un cierto "acoplamiento" de mi ser y actividad con los otros y entre los otros. "Caber" es estar entre los otros sin que estos impidan mi vida. Y no sólo por el asesinato directo, “de ahí la importancia del no matarás", nos decía Ellacuría, en cualquier catálogo de derechos, pero también del "asesinato indirecto" en modo de exclusión desde las prácticas sociales, económicas, políticas, culturales que impiden o dificultan las prácticas de otros en su dimensión social, de satisfacción de las necesidades materiales, de participación política, de construcción y expansión cultural. Y también, esa cabida hoy se reconoce desde la dimensión ecológica de intercambio con los otros seres vivos en el conjunto de la naturaleza. Ello implica la renuncia a un mundo donde tendencialmente sólo la especie humana, o más bien una minoría de ella, pueda desplegar libremente su actividad, mediante el empobrecimiento y exclusión creciente de la biodiversidad natural (y de la sociodiversidad humana).

34 En esta línea, hay que destacar los trabajos de una nueva teoría económica de Franz J. Hinkelammert y Henry Mora, ( 2002; 2006). 
Así las cosas, el disfrute de un derecho y en último término, de un modelo civilizatorio como el actual que sostiene y orienta normativamente un sistema de prácticas sociales, nos presenta otra cara siempre molesta y por reprimir de nuestra conciencia. Como nos recordaba el músico y poeta cubano Silvio Rodríguez, hay unos muertos de nuestra felicidad. En el difícil ajuste del mantenimiento de nuestra vida con sus prácticas legitimadas socialmente y el despliegue de éstas con los otros y con la realidad natural, hay costes sociales y ecológicos, a veces perdedores y también el sacrificio o la exclusión de otros que son condición de posibilidad de nuestro nivel o calidad de vida o de que podamos continuar ejerciendo nuestros derechos, o en última instancia el conjunto de nuestro modelo civilizatorio con todos sus subsistemas prácticos.

Por ello, la coexistencia de unos entre otros, implica un estar abierto positivamente a los otros con los que se convive, lo que permite la posibilidad de ser y estar para los otros y por los otros (solidaridad y don recibido), y ello libera dinámicamente la posibilidad de seguir siendo entre otros.

\section{Conclusiones}

El problema del ajuste interhumano, en suma, de hacernos cargo unos de otros para hacer viable la vida de todos y cada uno de los miembros de la especie, a la altura de nuestro proceso histórico, ya no se puede hacer desde un esquema culturalmente cerrado o autocentrado en una perspectiva meramente humana, es decir, que no contemple o se integre en una lucha por la sostenibilidad también de la naturaleza. En el último siglo, el desarrollo del nivel de vida en contextos primermundistas, se ha conseguido gracias un coste ecológico tal, que nuestro nivel de vida actual y nuestro modelo cultural de desarrollo humano se considera que es inviable para proseguir más allá de las próximas décadas. No damos ya tiempo a la naturaleza para autorregenerarse del impacto negativo sobre la misma. Pero lo decisivo para la cuestión de las prácticas normativas con los estándares de derechos humanos asentados es que éstos se posibilitan desde un modelo de desarrollo moderno que no es universalizable 
humana ni ecológicamente. Por ello, Ellacuría señaló con fuerza que hasta ahora, lo que se da no son derechos humanos universales y universalizables, sino de minorías. En este sentido tienen un carácter profundamente desajustado.

Por ello, estamos en un tiempo de desajustes globales que generan los diversos sentidos principales de la crisis actual. Por un lado la crisis de la exclusión social de millones de personas pero por otro, la crisis ecológica por el abuso de los recursos naturales y la alteración o destrucción de los ecosistemas en los que se sostenía la vida humana y que genera, a su vez, nuevas crisis sociales. Pero estos desajustes que hacen inviables para muchos la vida humana y no humana, tienen una fuente cultural o civilizatoria: los diferentes modos de habérselas con los otros y con la naturaleza en cada uno de los ámbitos que definen los procesos sociales actuales de la sociedad mundial. En función de las "externalidades" o de las disfunciones que globalmente genera esta civilización moderna avanzada, o "civilización de la riqueza y el capital" 35 como la denominaba Ellacuría, se puede ver el desajuste del horizonte cultural o civilizatorio actual como fuente de diversos desajustes del mundo actual por su responsabilidad en el proceso de globalización o de unificación fáctica de las condiciones de vida humana y no humana que se genera en el planeta. Hay y subsisten diversas tradiciones culturales y religiosas de la humanidad (que tiene a su vez que enfrentar sus propios desajustes internos o sus opresio-

35 Aun cuando se discrepe del juicio sociohistórico que en la línea crítica de Ellacuría se realiza sobre la civilización occidental como vector de la universalidad de los derechos humanos, se puede convenir en que la dimensión de ajuste o justeza fáctica y universal es algo perseguible como dimensión ineludible del mismo patrón normativo de los derechos humanos. En este sentido, diferentes juicios sobre el significado que la configuración práctica de nuestra civilización genera en el mundo de hoy, podrían ponerse de acuerdo sobre las implicaciones normativas del propio análisis de las prácticas jurídicas. Esto es lo que puede ofrecer una filosofía primera. El análisis ellacuriano complementa a su vez ese análisis integrando filosóficamente el conocimiento empírico de la sociedad global y de su mundo natural que nos ofrecen las ciencias sociales y naturales acerca de la situación y del proceso que se está desplegando en ese mundo empírico. En esa complementariedad, es donde la filosofía práctica debe recapitular su trabajo de orientación global de la praxis humana, aunando el análisis filosófico fundamentado con pretensión de radicalidad y el conocimiento científico actual, en un análisis filosófico global integrado aun cuando ello suponga una mayor incertidumbre y provisionalidad en sus resultados. 
nes particulares), pero estas tradiciones se configuran en buena medida en sus sistemas de vida desde un patrón cultural o civilizatorio hegemónico desde el cual luchan por la supremacía los diversos grupos sociales de la humanidad. Estas tradiciones apenas tienen fuerza para configurar prácticamente las interacciones jurídicas, económicas, científicas, tecnológicas o ecológicas en el conjunto de la humanidad, sino que se definen por usar los mismos recursos culturales que los países de origen occidental en la lucha por la supremacía.

En este sentido, la crisis de la civilización moderna no se resuelve por la adopción de otras alternativas civilizatorias colonizadas con pretensión hegemónica, sino desde la lucha intercultural por enfrentar los supuestos básicos de la matriz cultural moderna, que hoy es global. Por ello, la generación de otro horizonte cultural postmoderno a partir de las prácticas sociales críticas que se articulan interculturalmente desde diversas tradiciones occidentales y no occidentales tienen en común tratar de enfrentar los límites de la matriz cultural moderna. El propio Ellacuría era consciente del problematismo y del desajuste, porque lo podía visibilizar ya desde su contexto histórico, de esa matriz que ha configurado con éxito la sociedad global, pero cuyo éxito es también el propio problema. Traigamos a colación su propio análisis: "Al tratar de concretar algunas de las ideologías que mantienen y justifican esta situación nos referimos a aquella visión que limita al hombre a su ser económico (consumidorproductor) y político (ciudadano abstracto disminuido y manipulado), que reduce la naturaleza a simple recurso económico y que relega a Dios a ciertas funciones reguladoras. Este horizonte cultural dominante, cuya matriz explicativa se encuentra en la Ilustración, debe ser juzgado desde sus efectos negativos: Masa de personas excedentes, naturaleza saqueada y destruida, Dios funcionalizado... Y de un modo global, ruptura de relaciones humanizadoras y fundantes" (Ellacuría, 2010). Esa ruptura de las relaciones humanizadoras y fundantes, en síntesis expresa los límites de la Modernidad y su propia fecundidad histórica.

El desajustamiento que la actividad humana desde la civilización moderna está generando no puede ser sin más solucionado simplemente desde sus mismos supuestos básicos, sin un cuestionamiento del marco cultural en el que se funda. De algún modo tiene que ser reordenado 
y reorientado en un nuevo horizonte de intelección, que hoy se presenta como necesidad y que se va construyendo en diversas prácticas críticas contrahegémónicas en la lucha por hacer posible no solo otros mundos en este, sino el mismo mundo en el que quepan otros. Los problemas ecológicos y sociales de nuestra época nos hacen cuestionarnos el problematismo del horizonte de la subjetividad moderna. Nos decía Zubiri que un horizonte cultural entra en crisis cuando las cosas "no encajan bien". Cuando el marco desde el que se entienden y son tratadas, se presenta como incapaz de tratar debidamente a las mismas; por tanto, cuando ese ámbito o lugar es visto como la fuente misma del desajuste de las respuestas humanas frente a lo real.

Si el ser humano no es mero trozo del universo, como denunció la Modernidad, tampoco es su envolvente virtual, sino que, como avanzó Ellacuría, es ambas en intrínseca codeterminación, aunque ese "ambas cosas" esté todavía por construir. Habría que considerar el último siglo como aquel donde se ha hecho visible la dificultad de la Modernidad para articular las respuestas humanas frente a las exigencias de lo real. En cierto modo, esta conciencia de la crisis es el punto desde el que se gesta el intento de superación de los desajustes presentes. Esta crisis cultural es interior al occidente, pero no se puede afrontar a mi juicio sin una escucha de otras voces que nacen de otros lugares, de otros supuestos culturales negados que interpelan al vigente. Sin embargo, el nuevo horizonte que provea otros ajustes de las acciones humanas con lo real para nosotros, no parte de cero, sino que tiene que transformar críticamente la Modernidad en otro camino de nueva síntesis que no puede ser simplemente un abandono ingenuo e indolente de lo realizado. Se trata, a mi juicio, no ya de contraer el horizonte, como hizo la Modernidad con respecto al anterior, sino de un proceso de ampliación al que socialmente estamos abocados y del que normativamente empezamos a detectar nuevas consecuencias modificando nuestro modo de relación con los otros, lo natural externo y la naturaleza que nos constituye. En este sentido, lo postmoderno de las prácticas críticas reside en la reconstitución de las relaciones humanizadoras y fundantes, lo cual no tiene nada que ver con el "postmodernismo" agotado que opera desde la misma ruptura de relaciones que estableció la Modernidad. 


\section{Referências}

ALEXY, ROBERT. La institucionalización de la justicia. Granada: Comares, 2005.

ANDRÉS IBÁÑEZ, PERFECTO. "Prólogo" en FERRAJOLI, LUIGI, Derechos y garantías. La ley del más débil. Madrid: Trotta, 1999. ARISTÓTELES. Ética a Nicómaco. (Trad. P. Azcárate). Madrid: Austral, 1982.

BEORLEGUI, CARLOS. "La filosofía de Ignacio Ellacuría en el contexto filosófico latinoamericano". Ignacio Ellacuría 20 años después: Actas del Congreso Internacional. España, Instituto Andaluz de Administración Pública, 2009.

BEORLEGUI, CARLOS. Historia del pensamiento filosófico

latinoamericano. Una búsqueda incesante de la identidad. Bilbao:

Universidad de Deusto, 2006.

CASTELLÓN MARTÍN, JOSÉ JOAQUÍN. Ellacuría y la filosofía de la praxis. Huelva: Hergué Editorial, 2003.

DUSSEL, ENRIQUE. "Algunas reflexiones sobre la falacia naturalista", In: Hacia una filosofía política crítica. Bilbao: Desclée de Brouwer, 2001.

DUSSEL, ENRIQUE. ¿Fundamentación de la ética? De Porfirio

Miranda a Ignacio Ellacuría. México: UAM-Iztlapalapa, 2007.

ELLACURÍA, I. [1985] "Función liberadora de la filosofía". In:

Escritos políticos I. San Salvador: UCA Editores, 1993.

ELLACURÍA, I. [1971] "Discurso de la Universidad Centroamericana "José Simeón Cañas" en la firma del contrato con el Banco Interamericano de Desarrollo (BID)". In: Escritos universitarios. San Salvador: Uca editores, 1999.

ELLACURÍA, I. [1975] "Sentido de la historia para la persona humana". In: Escritos filosóficos III. San Salvador: UCA Editores, 2001. 
ELLACURÍA, I. [1978] "El sujeto de la historia". In: Cursos universitarios. San Salvador: Uca editores, 2009.

ELLACURÍA, I. [1979] "Fundamentación biológica de la ética". In: Escritos filosóficos III. San Salvador: UCA Editores, 2001.

ELLACURÍA, I. [1981] "El objeto de la filosofía". In: Escritos políticos I. San Salvador: Uca editores, 1991.

ELLACURÍA, I. [1988] "La superación del reduccionismo idealista en Zubiri”. In: Escritos filosóficos III. San Salvador: UCA Editores, 2001.

ELLACURÍA, I. [1989] “El mal común y los derechos humanos”. In: Escritos filosóficos III. San Salvador: UCA Editores, 2001.

ELLACURÍA, I. [1989] "Hacia una conceptualización de los derechos humanos”. In: Escritos filosóficos III. San Salvador: UCA Editores, 2001.

ELLACURÍA, I. [1989] "Historización de los derechos humanos desde los pueblos oprimidos y las mayorías populares”. In: Escritos filosóficos III, San Salvador: Uca editores, 2001.

ELLACURÍA, I. "Dimensión ética de la filosofía". In: Actas del Congreso Internacional Ignacio Ellacuría 20 años después. Sevilla: Instituto Andaluz de Administración Pública, 2010.

ELLACURÍA, I. “Introducción. Persona y comunidad”. In: Escritos filosóficos III. San Salvador: UCA Editores, 2001.

ELLACURÍA, I. "Perspectiva histórico-ética de la filosofía latinoamericana". In: Actas del Congreso Internacional Ignacio Ellacuría 20 años después. Sevilla: Instituto Andaluz de Administración Pública, 2009.

ELLACURÍA, I. Principialidad de la esencia en Xavier Zubiri.

Madrid: Universidad Complutense, 1965.

FERRAJOLI, LUIGI. Derechos y garantías. La ley del más débil.

Madrid: Trotta, 1999.

GIMBERNAT, JOSÉ A; GÓMEZ, CARLOS. La pasión por la libertad. Homenaje a Ignacio Ellacuría, Estella: Verbo divino, 1994. 
GONZÁLEZ, A. Estructuras de la praxis. Ensayo de un filosofía primera. Madrid: Trotta, 1997.

GONZÁLEZ, ANTONIO. “Aproximación a la obra filosófica de Ignacio Ellacuría”. San Salvador: ECA, 505-506, 1990.

GRACIA, D. "Filosofía práctica". In: Actas del Congreso Internacional Ignacio Ellacuría 20 años después. Sevilla: Instituto Andaluz de Administración Pública, 2010.

GRAY, J. C. The Nature and Sources of the Law, New York: Columbia University Press, 1948.

HART, H. L. A. (1961) El concepto del Derecho. (Trad. G. R. Carrió). Buenos Aires: Abeledo-Perrot, 1998.

HINKELAMMERT, F. J.; MORA, H. Hacia una economía para la vida. San José: DEI, 2006.

HINKELAMMERT, F. J.; MORA, H. Coordinación social del trabajo, mercado y reproducción humana. San José: DEI, 2002.

HINKELAMMERT, F. J. "La universidad frente a la globalización". In: El sujeto y la ley. El retorno del sujeto reprimido. Costa Rica: Heredia, 2003.

KELSEN, HANS. Teoría General del Derecho y del Estado [1949]. (Trad. E. García Máynez). México: Universidad Nacional Autónoma de México, 1988.

KELSEN, HANS. Teoría Pura del Derecho [1960]. (Trad. R. J. Vernengo). México: Ed. Porrúa, 2000.

MORA GALIANA, JOSÉ. Ignacio Ellacuría, filósofo de la liberación. Madrid: Editorial Nueva Utopía, 2004.

ORTEGA Y GASSET, JOSÉ. “Una interpretación de la historia universal”. In: Obras Completas, v. 9. Madrid: Alianza Ed., 1983.

PÉREZ LUÑO, ANTONIO-ENRIQUE. "Abschied von Hans Kelsen? La metamorfosis actual de los sistemas jurídicos y su impacto en la teoría pura del derecho". In: La filosofía del derecho en perspectiva 
histórica. Estudios conmemorativos del 65 aniversario del autor, Sevilla: Universidad de Sevilla, 2009.

PUTNAM, HILARY. EI desplome de la dicotomía hecho-valor y otros ensayos. Barcelona: Paidós, 2004.

REAL ACADEMIA ESPAÑOLA. Diccionario de la lengua española. Madrid: Espasa, 1992.

RICOEUR, PAUL. Sí mismo como otro. Madrid: Siglo XXI, 1996. ROSILLO MARTÍNEZ, ALEJANDRO. Los derechos humanos desde el pensamiento de Ignacio Ellacuría. Prol. J. J. Tamayo. Madrid: Dykinson, 2009.

SAMOUR, HÉCTOR. Voluntad de liberación. El pensamiento filosófico de Ignacio Ellacuría. Granada: Comares, 2003.

SÁNCHEZ RUBIO, DAVID. Filosofía, Derecho y Liberación en América Latina. Bilbao: Desclée de Brouwer, 1999.

SENENT DE FRUTOS, J. A. "Ecología y problemas medioambientales. Orientaciones para la praxis desde otro marco cultural". Revista Fomento Social, n. 256, p. 699-708. Córdoba: Institución Universitaria de la Compañía de Jesús, 2009.

SENENT DE FRUTOS, J. A. "La tierra y la naturaleza en el horizonte de la subjetividad moderna". In: Die Bedeutung der Erde in den Kulturen. Zum Dialog der Kosmologien vor der ökologishen Herausforderung. Dokumentation des XIII. Internationalen Seminars des Dialogprogramms Nord-Süd, p. 179-182, Mainz: Aachen, 2009. SENENT DE FRUTOS, J. A. "Sujeto libre y discernimiento de la ley". Revista Isidorianum, n. 30. Sevilla: Centro de Estudios Teológicos, 2006.

SENENT DE FRUTOS, J. A. Ellacuría y los derechos humanos. Bilbao: Desclée de Brouwer, 1998.

SENENT DE FRUTOS, J. A. Problemas fundamentales de los derechos humanos. Valencia: Tirant lo Blanch, 2007. 
SENENT DE FRUTOS, JUAN ANTONIO. Problemas fundamentales de los derechos humanos desde el horizonte de la praxis. Valencia: Tirant lo Blanch, 2007.

SENENT DE FRUTOS, JUAN ANTONIO; MORA GALIANA, JOSÉ. In: Actas del Congreso Internacional Ignacio Ellacuría 20 años después. Sevilla: Instituto Andaluz de Administración Pública, 2010. SERRANO, JOSÉ LUIS. Validez y vigencia. La aportación garantista a la teoría de la norma jurídica. Madrid, Trotta, 1999.

SOBRINO, J.; ALVARADO, R. Ignacio Ellacuría, “Aquella libertad esclarecida". Santander: Sal Terrae, 1999.

WEBER, MAX, "Roscher y Knies y los problemas lógicos de la escuela histórica de economía". In: El problema de la racionalidad en las ciencias sociales. Ed. J. M. García Blanco. Madrid: Alianza, 1985. ZUBIRI, XAVIER. Inteligencia y logos. Madrid: Alianza, 1982. ZUBIRI, XAVIER. Inteligencia y razón. Madrid: Alianza, 1983. ZUBIRI, XAVIER. Inteligencia y realidad. Madrid: Alianza, 1980. ZUBIRI, XAVIER. Sobre el hombre. ed. I. Ellacuría. Madrid: Alianza, 1986. 